\title{
Incidence of Dental Caries and Periodontal Diseases among Adolescents Receiving Orthodontic Treatment in a Dental Institute in Virajpet
}

\author{
Rohith A. Nair ${ }^{1}$, Jitheesh Jain², Jaseela Praveena ${ }^{3}$, Keerthan Shashidhar, Pooja M.R. ${ }^{5}$, Shishir Shetty ${ }^{6}$ \\ 1,6 Department of Conservative Dentistry and Endodontics, A.B. Shetty Memorial Institute of Dental \\ Sciences, Mangalore, Karnataka, India. ${ }^{2,5}$ Department of Public Health Dentistry, Coorg Institute of Dental \\ Sciences, Virajpet, Kodagu, Karnataka, India. ${ }^{3}$ Department of Public Health Dentistry, K.V.G Dental College \\ and Hospital, Sullia, Mangalore, Karnataka, India. ${ }^{4}$ Department of Orthodontics and Dentofacial \\ Orthopaedics, A.B. Shetty Memorial Institute of Dental Sciences, Mangalore, Karnataka, India.
}

\section{ABSTRACT}

\section{BACKGROUND}

The purpose of this study was to determine the incidence of dental caries and periodontal diseases among adolescent subjects receiving orthodontic treatment in a dental institute.

\section{METHODS}

This cross-sectional study was conducted in the Department of Orthodontics and Orthopaedics, Coorg Institute of Dental Sciences, Virajpet, among 12-18-year-old subjects receiving orthodontic treatment from Coorg Institute of Dental Sciences, Virajpet. The data collected was coded and analysed using SPSS (Statistical Package for Social Sciences, version 21). Descriptive statistics included the frequency, percentage, mean and standard deviation.

\section{RESULTS}

Incidence of dental caries was found to be $100 \%$ (90) and incidence of gingival bleeding was found to be $100 \%$ (90) among subjects receiving orthodontic treatment. About $94 \%$ of study subjects did not have any oral mucosal conditions while $6 \%$ study subjects had oral mucosal conditions.

\section{CONCLUSIONS}

The results showed that there was a high incidence of dental problems such as dental caries and periodontal disease among orthodontic patients while incidence of oral mucosal conditions was found to be $6 \%$. Orthodontic practitioners should stress upon the importance of maintaining proper oral hygiene to their patients. Hence, periodic evaluation is necessary to diagnose and treat these diseases at an early stage.
Corresponding Author: Dr. Jaseela Praveena, Department of Public Health Dentistry, K.V.G Dental College and Hospital. Kurunjibag, Sullia - 574327, Mangalore, Karnataka, India E-mail: jaz3p91@gmail.com

DOI: $10.14260 /$ jemds/2021/239

How to Cite This Article:

Nair RA, Jain J, Praveena J, et al. Incidence of dental caries and periodontal diseases among adolescents receiving orthodontic treatment in a dental Institute in Virajpet. $J$ Evolution Med Dent Sci 2021;10(16):11191122, DOI: $10.14260 /$ jemds/2021/239

Submission 10-12-2020,

Peer Review 20-02-2021, Acceptance 26-02-2021, Published 19-04-2021.

Copyright (C) 2021 Rohith A. Nair et al. This is an open access article distributed under Creative Commons Attribution License [Attribution 4.0 International (CC BY 4.0)]

\section{KEY WORDS}

Caries, Periodontal Diseases, Incidence, Orthodontics, Dental Institute 


\section{BACKGROUND}

Malaligned or malpositioned tooth apart from resulting in various problems like aesthetics, function, dysfunction of the temporo-mandibular joint, problems with swallowing and speech, susceptibility to facial traumatic injuries are also risk factors for both dental caries and periodontal conditions. It makes oral hygiene practices difficult by providing safe harbour for food particles to lodge or by increased plaque accumulation which in turn is the main factor leading to the most prevalent dental diseases. However, "As mal aligned teeth are a risk for periodontal and so is the treatment for it." Orthodontic treatment, as it involves usage of removable or fixed orthodontic appliances especially brackets and ligation over long period of time have their inherent disadvantage of creating new retention areas in addition to blocking plaqueremoving shear forces arising from fluid flow and masticatory loads with a resultant undesired effect of accumulation of dental plaque in turn increasing amount of dental plaque containing cariogenic bacteria causing decalcification of enamel during the treatment. ${ }^{1,2-4}$

Orthodontic treatment not only helps the patients in improving dental and facial aesthetics thereby improving selfesteem but also improves dental occlusion by aligning the teeth properly, which ultimately results in good functioning of dentition. ${ }^{1}$ Even though orthodontic treatment will result in positive change in periodontitis and caries experience, the conditions can turn for the worse during the said procedure. Along with the benefits of orthodontic procedures, patients might face many a complication while undergoing the treatment. It is reported that $95 \%$ of the orthodontic patient's experience varying degree of pain during orthodontic treatment due to the margins of orthodontic bands impinging on the gingival area.5-7 Plaque accumulation in the sub gingival bands and brackets can be a factor in the development of periodontal problems. Gingivitis are common in patients who do not employ proper oral hygiene measures. Patients also exhibit gingival hypertrophy, bleeding, increased plaque accumulation, and calculus formation during orthodontic treatment.8,9 Thus, appropriate oral hygiene measures and preventive procedures are recommended as bands, brackets, ligature wires, and elastics encourage the accumulation of the plaque over time around orthodontic appliances resulting in gingivitis, periodontitis and dental caries.3,4,8

The purpose of this study was to find the incidence of dental caries and periodontal diseases among adolescent subjects receiving orthodontic treatment in a dental institute.

\section{METHODS}

This cross-sectional study was conducted from September 2017 to February 2018 in the Department of Orthodontics and Orthopaedics, Coorg Institute of Dental Sciences, Virajpet. Data was collected from the Department of Orthodontics and Orthopaedics. Coorg Institute of Dental Sciences, Virajpet. Ethical clearance was obtained from the institutional review board of Coorg Institute of Dental Sciences, Virajpet. 12 - 18 year-old subjects receiving orthodontic treatment from the institute who had no caries, gingivitis or mucosal lesions at the time of starting their orthodontic treatment, have undergone treatment for 6 - 12 months and have assented to participate with the consent of the parents were included in the study.
Subjects who were having systemic diseases and who were under medication were excluded. The participants fulfilling the inclusion exclusion criteria were included in the study after obtaining written Informed consent from the concerned parents. A pilot study was conducted on 10 subjects to check for the validity and reliability of the questionnaire. Content validation was done using Content Validity Index (CVI) and reliability score Cronbach's alpha value was calculated to be 0.8217 (good). These 10 subjects were not included in the final sample. Convenient sampling technique was followed in the selection of subjects. Sample size of 90 subjects were finally included in the study. Data was collected for a period of two months (February 2017 - March 2017) using a standardised proforma containing two parts. The first part includes questions pertaining to basic demographic details, diet history and oral hygiene practices. The second part was to record dentition and periodontal status by using World Health Organization (WHO's) Oral Health Assessment Proforma for children (2013). The language of the questionnaire was English, and it was a multiple choice close ended question.

\section{Statistical Analysis}

The data was collected, coded and fed into the SPSS (Statistical Package for Social Sciences, version 21) for statistical analysis. Descriptive statistics like mean and standard deviations as well as frequency and percentage were analysed.

\section{RESULTS}

The study participants comprised of 90 subjects, 44 males and 46 females ( $49 \%$ and $51 \%$ respectively). Mean age of study subjects was found to be 15.656 with standard deviation of 1.1135. Subjects studying in $8^{\text {th }}$ standard was found to be 1 (1.10\%), 9 th $^{\text {standard } 15}(16.70 \%), 10^{\text {th }}$ standard $27(30 \%)$, $11^{\text {th }}$ standard $20(23.30 \%)$ and $12^{\text {th }}$ standard $27(30 \%)$ respectively as shown in Table 1.

\begin{tabular}{|c|c|c|c|c|}
\hline Sl. No. & Parameters & & Number & $(\%)$ \\
\hline \multirow[t]{2}{*}{1} & \multirow[t]{2}{*}{ Gender } & Males & 44 & $49 \%$ \\
\hline & & Females & 46 & $51 \%$ \\
\hline \multirow{7}{*}{2} & \multirow{5}{*}{ Class } & $8^{\text {th }}$ standard & 1 & 1.10 \\
\hline & & $9^{\text {th }}$ standard & 15 & 16.70 \\
\hline & & $10^{\text {th }}$ standard & 27 & 30 \\
\hline & & $11^{\text {th }}$ standard & 20 & 22.20 \\
\hline & & $12^{\text {th }}$ standard & 27 & 30 \\
\hline & & & Mean & Std. deviatior \\
\hline & & Mean age of study subjects & 15.656 & 1.1135 \\
\hline & Table 1. Dem & iphic Details of the Stu & dy Popula & tion \\
\hline
\end{tabular}

\begin{tabular}{|cccc|}
\hline \multirow{2}{*}{ Question } & Response & \multicolumn{2}{c|}{ Study Subjects } \\
Type of toothbrush & Normal toothbrush & 0 & Percentage \\
& Orthodontic toothbrush & 90 & $100 \%$ \\
Method of cleaning & Circular & 43 & $47 \%$ \\
& Horizontal & 47 & $53 \%$ \\
Frequency of brushing & Once & 72 & $80 \%$ \\
& Twice & 18 & $20 \%$ \\
Time of brushing & Before meals & 57 & $64 \%$ \\
Materials used & After meals & 33 & $36 \%$ \\
Use of any other oral & Toothpaste & 90 & $100 \%$ \\
hygiene aids & Yes & 53 & $58 \%$ \\
\hline Table 2. Distribution of Oral Hygiene Practices among Study Subjects \\
\hline
\end{tabular}




\begin{tabular}{|lccc|}
\hline Disease & Variables & Mean & Std. Deviation \\
& Number of sound teeth & 21.233 & 1.943 \\
Dental caries & Number of teeth with caries & 6.3222 & 2.081 \\
\cline { 2 - 4 } & Number of teeth filled due to caries & 0.40 & 1.140 \\
\cline { 2 - 4 } Periodontal & DMFT & 6.7222 & 1.9604 \\
disease & Absence of gingival bleeding & 21.977 & 1.655 \\
\hline Table 3. Assessment of Periodontal Status and Dental Caries in Study & \multicolumn{3}{|c|}{ Subjects } \\
\hline
\end{tabular}

\begin{tabular}{|cccc|}
\hline \multirow{2}{*}{ Condition } & Variables & \multicolumn{2}{c|}{ Study Subjects } \\
& & Number & Percentage \\
Oral mucosal & Absent & 84 & $94 \%$ \\
conditions & Present & 6 & $6 \%$ \\
\hline Table 4. Distribution of Oral Mucosal Conditions among Study Subjects
\end{tabular}

All the subjects used orthodontic toothbrush for brushing their teeth $(100 \%)$. Around $47 \%$ of study subjects used circular motion as method of cleaning and $53 \%$ used horizontal motion as method of cleaning respectively. Around $80 \%$ of study subjects brushed only once while $20 \%$ of study subjects brushed twice a day. Around $64 \%$ of study subjects brushed their teeth before meals, while $36 \%$ study subjects brushed their teeth after the meals. All the subjects used tooth paste for brushing. Around $58 \%$ of study subjects used other oral hygiene aids, while $42 \%$ study subjects did not use any oral hygiene aids. $39 \%$ study subjects were vegetarian and 61 $\%$ were following a mixed diet. Mean sugar score of study subjects were found to be 16.7778 with standard deviation of 5.045. The mean number of sound teeth was found to be $21.233 \pm 1.943$. Mean number of teeth with caries was found to be $6.3222 \pm 2.081$. Mean number of teeth filled with caries was found to be $0.40 \pm 1.140$. The mean DMFT value was found to be $6.7222 \pm 1.9604$ as shown in Table 3 .

Mean number of teeth with absence of gingival bleeding was found to be $21.977 \pm 1.655$. Mean number of teeth with presence of gingival bleeding was found to be $6.022 \pm 1.655$. Incidence of dental caries was found to be $100 \%$ (90) and incidence of gingival bleeding was found to be $100 \%$ (90) among subjects receiving orthodontic treatment as shown in Table 3. About $6 \%$ (6) study subjects had oral mucosal conditions while $94 \%$ (84) of study subjects did not present with any oral mucosal conditions as shown in Table 4.

\section{DISCUSSION}

Orthodontics is defined by profit as the area of dentistry concerned with the supervision, guidance and correction of the growing and mature dent facial structures, including those conditions that require movement of teeth or correction of mal relationships and malformations of related structures by the adjustment of relationships between and among teeth and facial bones by the application of forces and / or stimulation and redirection of functional forces within the craniofacial complex. ${ }^{9}$ However, while doing so the probability of incidence of other dental ailments are high due to the extended period of treatment and difficulty in maintaining oral hygiene due to the presence of intraoral appliances. In the present study, demographic details of study subjects showed that females (46) were found to be more in number as compared to males (44). These findings are in accordance with the study conducted by Akshay Gupta et al. ${ }^{10}$ where patients receiving orthodontic treatment in Maharashtra, females were 93 and males were 72 . We agree with this author, who stated that it may be because females are more conscious of aesthetics than males.

The mean age in the present study was found to be 15.656 which was found in accordance with the study conducted by Barcevic et al.11 Among children receiving orthodontic treatment in Spain where it was 17.234. In the present study, $53 \%$ of orthodontic patients used oral hygiene aids which was in contrast to the results of the study conducted by Sandhya Sreshta et al.12 Among Nepalese orthodontic patients, it was only $34 \%$ and the authors concluded that it may be because of lack of knowledge to use the oral hygiene aids properly and as it is time consuming.

In the present study, the incidence of dental caries among orthodontic subjects was found to be $100 \%$ which was higher than that of the results from the study conducted by Richter et al. ${ }^{13}$ where $75.2 \%$ had new carious lesion. Mean number of teeth with caries among orthodontic patients was found to be 6.322 which was similar to the study conducted by Margriton et al. ${ }^{14}$ in Colombia, which reported DMFT (D) to be 6.732. In the present study, number of sound teeth was found to be 21.233, which was in accordance with the study conducted by Kvam et al. ${ }^{15}$ in New Zealand, where it was found to be 19.233 .

The mean DMFT in the present study was found to be 6.722 , which was much higher than the results of the study conducted by Sandhya Sreshta et al. ${ }^{12}$ which reported mean DMFT of 2.564. Most of the studies have well established that orthodontic treatment is implicated for changing oral environment by providing retention sites for dental plaque and increases the risk of developing caries. Presence of dental disease like dental caries and periodontal disease depends on how well the orthodontist is able to motivate the patient to maintain oral hygiene using different aids.

In the present study, mean number of teeth without gingival bleeding was found to be 21.977, which was similar to the study conducted by Brett Eckley et al. ${ }^{16}$ Among Japanese population it was found to be 18.5776 . The mean number of teeth with gingival bleeding was 6.022, which was in contrast to the results of the study conducted by Barcevic et al. ${ }^{11}$ in Spain, where it was 2.556 . This may be because of proper oral hygiene aids used by the subjects and also by the proper reinforcement by the orthodontists during their monthly visits.

In the present study, the incidence of oral mucosal conditions was found to be $6 \%$ which was in contrast to the results of the study conducted by Kvam et al. ${ }^{15}$ where it was found to be $47 \%$. One of the reasons could be that the present study was conducted 6 months after the initial bonding, by which time patient will be adjusted to the brackets. Other thing could be that the chances of mucosal ulcer will be very high during the initial levelling and aligning phase, which will gradually decrease as the treatment progresses into higher arch wires.

\section{CONCLUSIONS}

There is high incidence of dental problems such as dental caries and periodontal disease among orthodontic patients. 
Even though the incidence of periodontal diseases was high, the mean number of teeth without gingival bleeding were more when compared to other studies. This may be because of proper oral hygiene aids used by the subjects and also by the proper reinforcement by the orthodontists during their monthly visits. Incidence of oral mucosal conditions was found to be only $6 \%$. Orthodontic practitioners should stress upon the importance of maintaining proper oral hygiene and advice their patients appropriate aids to do so along with preventive procedure like fluoride applications or sealant placement as it has a major role in preventing dental caries and periodontitis incidence during orthodontic treatment. ${ }^{17-20}$ There are many studies regarding the effectiveness of health education, oral hygiene maintenance, oral prophylaxis and use of fluoride application in reducing incidence of caries and periodontal diseases during orthodontic treatments. ${ }^{21-24}$ Hence, periodic evaluation is necessary to diagnose and treat these diseases at an early stage.

\section{Recommendations}

- Practitioners should stress upon the importance of maintaining proper oral hygiene and advice their patients regarding appropriate aids to do so in adjunct with preventive procedure like fluoride applications or sealant placement.

- Proper oral hygiene instructions and aids should be advocated to children undergoing orthodontic treatments.

- Proper reinforcements must be done during their monthly visits.

- Periodic evaluation is necessary to diagnose and treat these diseases at an early stage.

Data sharing statement provided by the authors is available with the full text of this article at jemds.com.

Financial or other competing interests: None.

Disclosure forms provided by the authors are available with the full text of this article at jemds.com.

\section{REFERENCES}

[1] Moyer RE. Handbook of Orthodontics. 4th edn. Chicago: Year Book Medical Publishers 1988: p. 65.

[2] Zaghrisson BU, Zachrisson S. Caries incidence and oral hygiene during orthodontic treatment. Scand J Dent Res 1971;79(6):394-401.

[3] Ogaard B, Rølla G, Arends J. Orthodontic appliances and enamel demineralization. Part 1. Lesion development. Am J Orthod Dentofacial Orthop 1988;94(1):68-73.

[4] Årtun J, Brobakken B0. Prevalence of carious white spots after orthodontic treatment with multibonded appliances. Eur J Orthod 1986;8(4):229-34.

[5] Shaw WC, Addy M, Ray C. Dental and social effects of malocclusion and effectiveness of orthodontic treatment: a review. Community Dent Oral Epidemiol 1980;8(1):3645.

[6] Navabi N, Farnudi H, Rafiei H, et al. Orthodontic treatment and the oral health-related quality of life of patients. J Dent (Tehran) 2012;9(3):247-54.
[7] Gwinnett AJ, Ceen RF. Plaque distribution on bonded brackets: a scanning microscope study. Am J Orthod 1979;75(6):667-77.

[8] Nalcaci R, Demirer S, Ozturk F, et al. The relationship of orthodontic treatment need with periodontal status, dental caries and sociodemographic factors. Scientific World Journal 2012;2012:498012.

[9] Proffit WR, Fields HW, Sarver DM. Contemporary orthodontics. St. Louis, Mo: Mosby Elsevier 2007.

[10] Gupta A, Singh K. Assessment of oral health problems in patients receiving orthodontic treatment. Dentistry 2015;5(2):1-3.

[11] Baricevic M, Mravak-Stipetic M, Majstorovic M, et al. Oral mucosal lesions during orthodontic treatment. Int J Paediatr Dent 2012;21(2):96-102.

[12] Dhami B, Sreshta P, Sreshta MR, et al. Assessment of periodontal health in nepalese orthodontic patients. Orthodontic Journal of Nepal 2013;3(1):26-30.

[13] Martignon S, Ekstrand KR, Lemos MI, et al. Plaque, caries level and oral hygiene habits in young patients receiving orthodontic treatment. Community Dent Health 2010;27(3):133-8.

[14] Richter AE, Arruda AO, Peters MC, et al. Incidence of caries lesions among patients treated with comprehensive orthodontics. Am J Orthod Dentofacial Orthop 2011;139(5):657-64.

[15] Kvam E, Bondevik O, Gjerdet NR. Traumatic ulcers and pain in adults during orthodontic treatment. Community Dent Oral Epidemiol 1989;17(3):154-7.

[16] Alstad S, Zachrisson BU. Longitudinal study of periodontal condition associated with orthodontic treatment in adolescents. Am J Orthod 1979;76(3):277-86.

[17] Eckley B, Thomas J, Crout R, et al. Periodontal and microbiological status of patients undergoing orthodontic therapy. Hong Kong Dent J 2012;9(1):11-20.

[18] Bergamo AZ, De Oliveira KM, Matsumoto MA, et al. Orthodontic appliances did not increase risk of dental caries and periodontal disease under preventive protocol. Angle Orthod 2019;89(1):25-32.

[19] Clark JR. Oral hygiene in the orthodontic practice: motivation, responsibilities and concepts. Am J Orthod 1976;69(1):72-82.

[20] Zachrisson BU. Fluoride application procedures in orthodontic practice, current concepts. Angle Orthod 1975;45(1):72-81.

[21] Geiger AM, Gorelick L, Gwinnett AJ, et al. Reducing white spot lesions in orthodontic populations with fluoride rinsing. Am J Orthod Dentofacial Orthop 1992;101(5):403-7.

[22] Geiger AM, Gorelick L, Gwinnett AJ, et al. The effect of a fluoride program on white spot formation during orthodontic treatment. Am J Orthod Dentofacial Orthop 1988;93(1):29-37.

[23] Corry A, Millett DT, Creanor SL, et al. Effect of fluoride exposure on cariostatic potential of orthodontic bonding agents: an in vitro evaluation. J Orthod 2014;30(4):323-9.

[24] Alexander SA, Ripa LW. Effects of self-applied topical fluoride preparations in orthodontic patients. Angle Orthod 2000;70(6):424-30. 